\title{
Prevalence and Etiology of Abscess Disease of Sheep and Goats at Qassim Region, Saudi Arabia
}

\author{
Khaled Bani Al-Harbi \\ Department of Veterinary Medicine, \\ College of Agriculture and Veterinary Medicine, Qassim University, \\ PO Box 6622, Buraydah, Saudi Arabia \\ * Corresponding author email: aboabdelelah17@hotmail.com \\ Received: 28-05-2011, Accepted: 11-06-2011, Published Online: 22-09-2011 \\ doi: $10.5455 /$ vetworld.2011.495-499
}

\begin{abstract}
Abscess disease (caseous lymphadenitis and Morel disease) is a worldwide contagious bacterial disease of sheep and goats and is adversely affecting the development of the sheep industry in Saudi Arabia. Fifteen sheep and 12 goat farms at Qassim region, central Saudi Arabia, were surveyed during September and October 2008 for the determination of the prevalence and the etiology of abscess disease. One hundred and twenty pus samples were collected from affected external lymph nodes of clinically-ill sheep and goats and from infected internal lymph nodes and organs condemned during meat inspection in the slaughterhouses, for the isolation and identification of pathogenic bacteria causing sheep abscess disease. The prevalence of abscess disease varied between 5\%- 44.1\% in sheep farms, being highest in the Najdi breed, and between $2.2 \%-6.5 \%$ in goat farms. Males of both sheep and goats had the highest rate of infection compared to females $(\mathrm{p}<0.01)$. Bacterial isolates were obtained from 97 out of the 120 collected pus samples $(80.83$ $\%)$. The remaining 23 samples were sterile. Corynebacterium pseudotuberculosis and Staphylococcus aureus subsp. anaerobius accounted for about $54 \%$ of isolates, with almost equal frequencies $(\mathrm{p}=0.5)$. Other pyogenic bacteria such as $S$. aureus, Streptococci, Pseudomonas aeruginosa, Actinomyces pyogenes were also isolated from infected abscesses. They represented about $46 \%$ of the isolated etiological agents of sheep abscesses. This explains why available vaccines (bactrins) against caseous lymphadenitis (CLA) are poorly protective against abscess disease in Saudi Arabia.
\end{abstract}

Keywords: Abscess disease, sheep and goats, bacterial isolates, Qassim, Saudi Arabia.

\section{Introduction}

Abscess disease, commonly known as Morel's disease and caseous lymphadenitis (pseudotuberculosis) deserves interest because of its contagious nature, worldwide distribution and lack of effective control measures. It is primarily a disease of sheep and goats, and once introduced into a flock, it is very difficult to control because of its poor response to treatment, its ability to persist in the environment and the limitations in detecting subclinically infected animals (Ivanovic et al., 2009; Williamson, 2001). Morel's disease is caused by Staphyloccocus aureus subsp. anaerobius, that exists as a single bacterial clone worldwide (de la Fuente et al., 2010; Elbir et al., 2010). Caseous lymphadenitis is characterized by formation of abscesses in external and internal lymph nodes and is caused by Corynebacterium pseudotuberculosis (Baird and Fontaine, 2007). Some sheep breeds were found to be more susceptible to the disease than others (Pepin et al., 1988).
The losses caused by CLA may become important when its prevalence is high, particularly in countries with large numbers of sheep such as Australia. The losses are caused by condemnation and downgrading of carcasses and skin in abattoirs as well as reduction in wool growth (Paton et al., 1988, 1994; Williamson, 2001).

Previous studies (Paton et al., 1988; De la Fuente et al., 1997) have indicated spread of CLA mostly occurred around the time of shearing. Several modes of transmission of CLA during shearing have been suggested and there are evidence incriminating the lungs in the transmission of the disease (Ellis et al., 1987). Corynebacterium pseudotuberculosis was isolated from the tracheae of sheep with lung abscesses, which indicated that the lung transmits CLA through aerosol contamination of skin cuts of uninfected sheep.

There is no available vaccine that is known to confer solid immunity against Abscess disease. Production of effective vaccines targeting known 
Prevalence and Etiology of Abscess Disease of Sheep and Goats at Qassim Region, Saudi Arabia

Table-1. The origin of pus samples from sheep and goat abscesses used for bacterial isolation

\begin{tabular}{|c|c|c|c|c|}
\hline Sample & Sheep & Goats & Subtotal & Isolation \\
\hline External lymph nodes & 30 & 2 & 32 & 30 \\
\hline Internal organs* & 7 & 1 & 8 & 6 \\
\hline Total & 112 & 8 & 120 & 97 \\
\hline
\end{tabular}

C. pseudotuberculosis antigens is advised (Dorella et al., 2009). In some countries where vaccines are available, vaccination failure is blamed on improper implementation of CLA vaccination program (Paton etal., 2003).

Abscess disease is endemic in Saudi Arabian sheep and goat farms, and despite genuine efforts to control it by vaccination and culling, its prevalence remained high. Sheep farmers complain of poor response to available vaccines (killed formalized bacterins). The disease is threatening the development of the sheep industry in the Kingdom mainly because of the low sale value of infected sheep in the market especially during Hajj (annual Muslim pilgrim to Mecca) period. This paper describes the prevalence and etiology of abscess disease of sheep and goats in Qassim region, central Saudi Arabia.

\section{Materials and methods}

Survey: A survey was conducted during SeptemberOctober 2008 for the detection of the rate of infection with abscess disease in sheep and goat farms at Qassim region, central Saudi Arabia. Qassim region lies in the middle of the Arabian desert where sheep, goats and camels are the main livestock in the area. Occasionally, small amounts of rain falls during winter leading to growth of annual pasture for grazing animals. Animals are either kept by nomadic Bedouins or in intensively producing modern farms.

The purpose of the survey was to collect basic information on the epidemiology and etiology of abscess disease in the area following complaint of farmers about the increasing spread of abscesses in their sheep and goats flocks and also about the poor response to vaccination against abscess disease. Fifteen sheep (one in the animal market) and 12 goat flocks in intensively producing farms were surveyed for the prevalence of abscesses in relation to breed, age and sex of affected sheep and goats.

Microbiological studies: One hundred and twenty pus samples were collected from sheep and goats with clinical abscesses as well as from infected lymph nodes condemned during meat inspection in slaughterhouses. Intact swollen lymph nodes were taken to the laboratory for bacterial cultivation and identification. The origin and number of collected pus samples is given in Table-1. Pus samples were collected from intact abscesses only to avoid external contamination. The external surface of the affected lymph node was wiped with $70 \%$ alcohol before collection to avoid external contamination. The pus contents were aspirated using sterile $20 \mathrm{ml}$ syringe with wide gauge needle. After collection, samples were labeled and taken to the laboratory within 1-3 hours.

Different media were prepared and sterilized according to the manufacturer instructions. Blood was collected for the preparation of blood agar medium, under strict sterile conditions, from the jugular vein of a healthy sheep with no history of abscesses or vaccination. Collection was performed using acid citrate dextrose (ACD) blood collection bags. Blood was added to brain heart infusion agar base (Difco) after autoclaving and cooling down to $\sim 50-55^{\circ} \mathrm{C}$ and the medium was poured into sterile plastic Petri plates after mixing.

Cultivation: Each pus sample, collected in a syringe, was put into a sterile plate, and a sterile cotton swab was used to mix the sample thoroughly. Pus was then streaked onto brain heart infusion agar plate supplemented with $10 \%$ sheep blood. Similarly, a swab was taken from the edge of the lesion very close to the abscess wall followed by streaking the swabs onto the surface of blood brain heart infusion agar plate supplemented with $10 \%$ sheep blood.

Inoculated plates were incubated at $37{ }^{\circ} \mathrm{C}$ and checked for growth daily for up to 5 days. An additional plate was inoculated with each sample and incubated anaerobically using the Oxoid Gas-Pak jar and anaerobic environment-bearing envelope for isolation of $S$. aureus subsp. anaerobius.

I dentification of the isolates: Bacterial colonies were identified on the bases of colonial, morphological and characteristics as well as biochemical activities (Quinn et al., 1994; Carter and Wise, 2004). Smears were prepared from each colony type and stained with Gram's for microscopic examination. Different isolates were then preserved in semisolid 
brain heart infusion agar for further studies. Catalase positive S.aureus isolates were confirmed with BBL $^{\text {TM }}$ Staphyloslide ${ }^{\text {TM }}$ Latex Test (BD Diagnostic Systems, MD, USA). S. aureus subsp. anerobius were identified by its anaerobic growth on blood agar and negative mannitol fermentation and positive maltose fermentation with acid production. Corynebacterium psudotuberculosis were identified using API®coryne strips according to the manufacturer instructions concerning culture preparation, inoculation, and interpretation (bioMerieux ${ }^{\circledR S A}$, Lyon, France). Each strip contained 20 tests plus catalase which was applied in the same strip using $3 \% \mathrm{H}_{2} \mathrm{O}_{2}$. Identification of Pseudomonas aeruginosa isolates was based on its production of greenish exopigments and oxidase enzyme detected by freshly prepared $1 \% \alpha$-naphthol in $95 \%$ ethanol and a $1 \%$ aqueous solution of paminodimethylaniline oxalate. Arcanobacterium (Actinomyces) pyogenes was characterized by its beta hemolytic glistening colonies after 48 hours on blood agar. On biochemical testing, A. pyogenes was positive for gelatinase and negative for both catalase and nitrate reduction tests.

Statistical analysis: Results, where applicable, were analysed for the level of significance between means using a computer-adapted statistical programme, Instat 2.

\section{Results}

Survey Results: The results of the survey for sheep abscess disease are shown in Tables- 2 .

Table-2. Prevalence rate of Abscess disease in 15 sheep flocks in Qassim region

\begin{tabular}{lcc}
\hline Location & Flock No. & Percentage \\
\hline Al-Melaidah & $1-4$ & 20 \\
Ah-Hadeyah & 5 & 5.83 \\
Al-Atsh & $6-8$ & 44.11 \\
Gibah & 9 & 15.5 \\
Gossaibah & 11 & 1.1 \\
Butain & 12 & 10.5 \\
Unaizah & 13 & 5 \\
Al-Busr & 14 & 21.95 \\
Animal market & 15 & 10.91 \\
\hline
\end{tabular}

Sheep flock-size ranged between 40 and 1000 heads and included the major breeds of sheep in Qassim area (Najdi, Nuaimi and Sakni). The morbidity rate of the disease ranged between 1.1 and $44 \%$. The highest infection rate $(42 \%)$ was found in Najdi breed (22.4\%) followed by the Sakni breed (20 $\%)$ and the Naimi breed $(4.8 \%)$. The age group with highest disease prevalence in sheep is between 7 and 11 months, but abscess were seen in lambs at about two months of age and in adult sheep to up 3 years. Males had the highest morbidity rate $(68 \%)$ compared to females $(32 \%)$.

Among goats, the disease was found in 4 out of 12 flocks (Table-3) and then only few individual animals were affected. Nine goats were recorded with abscesses out of 572 examined goats, the prevalence being about $1.57 \%$. Prevalence was highest in flocks mixed with sheep or when the general health of the flock was poor.

Table-3. Prevalence of abscess disease among goats in 12 flocks at Qassim Region.

\begin{tabular}{|c|c|c|c|c|c|}
\hline $\begin{array}{l}\text { Flock } \\
\text { No. }\end{array}$ & $\begin{array}{l}\text { No. of } \\
\text { Animals }\end{array}$ & $\begin{array}{c}\text { No. of } \\
\text { Affected }\end{array}$ & $\begin{array}{c}\% \\
\text { Affected }\end{array}$ & Remarks & \\
\hline 1 & 25 & 0 & 0 & \multicolumn{2}{|c|}{ Very healthy flock for breeding } \\
\hline 2 & 35 & 0 & 0 & & \\
\hline 3 & 49 & 0 & 0 & " & " \\
\hline 4 & 22 & 0 & 0 & \multirow{2}{*}{\multicolumn{2}{|c|}{ Thin animals are affected }} \\
\hline 5 & 14 & 1 & 6.6 & & \\
\hline 6 & 45 & 1 & 2.22 & \multicolumn{2}{|c|}{ Mixed with sheep with abscesses } \\
\hline 7 & 40 & 0 & 0 & \multicolumn{2}{|c|}{ Very healthy flock for breeding } \\
\hline 8 & 200 & 6 & 3 & \multicolumn{2}{|c|}{ Malnutrition, and crowded pens } \\
\hline 9 & 38 & 0 & 0 & \multicolumn{2}{|c|}{ Very healthy flock for breeding } \\
\hline 10 & 46 & 1 & 6.51 & \multicolumn{2}{|c|}{$\begin{array}{l}\text { Mixed with sheep affected with } \\
\text { abscess disease }\end{array}$} \\
\hline 11 & 32 & 0 & 0 & \multirow{2}{*}{\multicolumn{2}{|c|}{$\begin{array}{l}\text { Very healthy flock for breeding } \\
\text { Very healthy flock for breeding }\end{array}$}} \\
\hline 12 & 25 & 0 & 0 & & \\
\hline Total & 572 & 9 & 1.57 & & \\
\hline
\end{tabular}

Bacteriological results: Bacterial isolates were obtained from 97 out of the 120 collected pus samples $(80.83 \%)$. The rest of the samples were sterile. Table-4 shows the frequency of bacterial isolates from sheep and goat abscesses. Pure cultures of $S$. aureus were isolated from 12 samples (12.37\%) while S. aureus subspecies anaerobius was isolated from 25 samples (25.77\%). Pure cultures of C. pseudotuberculosis were isolated from 27 samples $(27.84 \%)$. Streptococci were isolated from 9 samples $(9.28 \%)$ and Pseudomonas aeruginosa was recovered from 6 samples $(6.18 \%)$. Three cultures were identified as Actinomyces pyogenes (3.09\%), two cultures were found to be Pasteurella multocida (2.06\%), while 3 cultures were identified as Proteus (3.09\%). Mixed cultures were obtained from ten samples. These mixed cultures were duplicates of C. pseudotuberculosis + Streptococci (3), Streptococci + Staphylococci (3), Actinomyces pyogenes + Streptococci (1), Actinomyces pyogenes + Pasteurella multocida (2), and S. aureus + Proteus species (1).

\section{Discussion}

The isolation rate of bacteria from infected internal and external lymph nodes was $80.83 \%$. This is considered a good isolation percentage as it is well known that the center of the abscess is almost sterile and some samples might contain no organisms especially when using syringes for collection. 
Prevalence and Etiology of Abscess Disease of Sheep and Goats at Qassim Region, Saudi Arabia

Table-4. The frequency of bacterial isolates from sheep and goat abscesses

\begin{tabular}{|c|c|c|c|c|}
\hline Isolate & sheep & Goats & Total & Percentage \\
\hline \multicolumn{5}{|l|}{ Pure cultures } \\
\hline C. pseudotuberculosis & 25 & 2 & 27 & 27.84 \\
\hline S. aureus & 11 & 1 & 12 & 12.37 \\
\hline Streptococcus species & 9 & 0 & 9 & 9.28 \\
\hline Actinomyces pyogenes & 2 & 1 & 3 & 3.09 \\
\hline $\begin{array}{l}\text { Proteus spp. } \\
\text { Mixed cultures }\end{array}$ & 2 & 1 & 3 & 3.09 \\
\hline C. pseudotuberculosis + Streptococcus species & 3 & 0 & 3 & 3.09 \\
\hline Streptococcus species + Actinomyces pyogenes & 0 & 1 & 1 & 1.03 \\
\hline S. aureus subsp. anaerobius $+\mathrm{S}$. aureus & 3 & 0 & 3 & 3.09 \\
\hline Actinomyces pyogenes + Pasteurella multocida & 2 & 0 & 2 & 2.06 \\
\hline
\end{tabular}

Results on prevalence of abscess disease in sheep in Qassim region and the highest prevalence of the disease in the Nadi breed conforms with many previous reports about the nature of this disease and its breed variations (Pepin et al., 1988). A $71 \%$ prevalence rate of abscess disease had been report in a Spanish sheep farm following shearing (De la Fuente et al., 1997) and a prevalence of about $21 \%$ was report for both Morel and CLA in Denmark by Meller et al., (2000).

Comparing the obtained results with previous studies, it can be noticed that there is agreement in that $C$. pseudotuberculosis and $S$. aureus were the most common causes of sheep and goat abscesses (Meller $e t$ $a l ., 2000)$. The results of this study point to the fact that Morel disease and CLA should be addressed as a one entity problem (Meller et al., 2000) when considering epidemiological studies in Saudi Arabia because of their equal prevalence in sheep and goat farms ( $p$ $=0.5$ ). It is also important that when considering control measures for abscess disease, especially vaccine production, the role of other pathogenic bacterial involved in the etiology of the disease should be taken into consideration. Sheep farmers at Qassim region complain of poor response to vaccination against abscess disease and our results have shown that $27.84 \%$ of abscesses were caused by $C$. Pseudotuberculosis and $25.77 \%$ were due to S. aureus anaerobius. There are still about $46 \%$ of etiologic agents of the disease not related to these two pathogens and these can significantly affect the vaccination outcomes.

\section{Acknowledgements}

The research work is supported by a generous grant from the Deanship for Research, Qassim
University. The technical help of Dr. Mahmoud Hashad is highly appreciated.

\section{References}

1. Baird, G. J. and Fontaine, M. C. (2007). Corynebacterium pseudotuberculosis and its role in ovine caseous lymphadenitis. J. comp. Pathol. 137, 179-210.

2. Carter, G. R. and Wise, D. J. (2004). Essentials of Veterinary Bacteriology and Mycology, 6th edition. Blackwell Publishing Professional, Ames, Iowa 50014, USA.

3. De la Fuente, R., Cid, D., Sanz, R. And Ruiz-Santa-Quiteria, J. A. (1997). An outbreak of abscess disease associated with shearing. Small Rumin. Res. 26 (3), 283-286.

4. De la Fuente, R., Balesteros, C., Bautista, V., Medina, A., Orden, J. A., Dominguez- Bernal, G. and Vindel, A. (2010). Staphyloccocus aurus subsp. Anaerobius isolates from different countries are clonal in nature. Vet. Microbiol., (Epub. ahead of print)

5. Dorella, F. A., Pacheco, L.G., Sayffert, N., Portela, R. W. Meyer, R., Miyoshi, A., Azevedo, V. (2009). Antigens of C. psuedotuberculosis and prospects for vaccine development. ExpertRev. Vacc. 8, 205-213.

6. Elbir, H., Edward, J. F., Drancourt, M., Veronique, R., El Sanousi, S. M., Eshag, M., Colque, P., Kunn, I. and Flock, J. (2010). Ovine clone ST1464: A predominant genotype of Staphylococcus aureus subsp. anaerobius isolated from Sudan. J. Infect. Dis. Develop. Count. 4, 235-238.

7. Ellis, T. M., Sutherlans, S. S., Wilkinson, F. C., Mercy, A. R. and Paton, M. W. (1987). The role of Corynebacterium pseudotuberculosis lung lesions in the transmission of this bacterium to other sheep. Austral. Vet. J. 64, 261 - 263.

8. Ivanovic, S., Zutic, I., Pavlovic, I. and Zujovic, M. (2009). Caseous lymphadenitis in goats. Biotech. Anim. 25 (5-6), 999- 1007.

9. Meller, K., Agerlholm, J. S., Ahrens, P., Jensen, N. E. and Nielsen, T. K. (2000). Abscess disease, caseous lymphadenitis and pulmonary adenomatosis in imported sheep. J. Vet.Med. (B) 47, 55-62.

10. Paton, M. W., Mercy, A. R., Wilkinson, F. C., Gardner, J. J. Sutherland, S. S. and Ellis, T. M. (1988). The effects of caseous lymphadenitis on wool production in young lambs. Austral. J. Vet. Res. 65, 117 - 119.

11. Paton, M. W., Rose, J. R. Hart, R. A. Sutherland, S. S. Mercy, A. R., Ellis, T. M. and Dhaliwal, J. A. (1994). New infection 
with Corynebacterium pseudotuberculosis reduces wool production. Austral. Vet. J. 71, 47-49.

12. Paton, M. W., Walker, S. B., Rose, I. R. and Watt, G. F (2003). Prevalence of caseous lymphadenitis and usage of caseous lymphadenitis vaccines in sheep flocks. Austral. Vet. J., 81(1-2), $91-95$

13. Pepin, M., Pardon, P. and Lantier, F. (1988). Corynebacterium pseudotuberculosis infection in adult ewes by inoculation in the external ear. Am. J. Vet. Res. $49,459-463$.

14. Quinn, P. J., Carter, M. E., Markey, B. K. and Carter, G. R (1994). Clinical Veterinary Microbiology. Wolfe Publishing, an imprint of Mosby-Year Book Europe Limited.

15. Williamson, L. H. (2001). Caseous lymphadenitis in small ruminants. Vet. Clin. North Am. Food Anim. Pract. 17, 359 371. 